\title{
ILF3 promotes gastric cancer proliferation and may be used as a prognostic marker
}

\author{
YÜ LIU, YONG LI, YIJIE ZHAO, YANG LIU, LIQIAO FAN，NAN JIA and QUN ZHAO \\ Department of General Surgery, Hebei Medical University Fourth Affiliated Hospital and \\ Hebei Provincial Tumor Hospital, Shijiazhuang, Hebei 050011, P.R. China
}

Received August 8, 2018; Accepted April 25, 2019

DOI: $10.3892 / \mathrm{mmr} .2019 .10229$

\begin{abstract}
Interleukin enhancer-binding factor 3 (ILF3) may function as a transcriptional coactivator and has been reported to be involved in tumor proliferation and metastasis; however, its role and clinical value in gastric cancer $(\mathrm{GC})$ remains unclear. To understand the value of ILF3 in GC, a total of 80 matched samples selected from GC tissues and the adjacent mucosa were used to evaluate the expression of ILF3 and its association with clinical characteristics. Furthermore, its biological functions and mechanisms were investigated using SGC-7901 and BGC823 cell lines. Immunohistochemistry demonstrated that the positive expression rates of ILF3 in GC tissue were higher compared with those in adjacent mucosa $(\mathrm{P}<0.05)$. Significantly overexpressed ILF3 was detected in BGC823 and SGC7901 cells, and the MTT results demonstrated decreased cell activity after ILF3 expression was inhibited. The proportions of cells in the G0/G1 phase increased, while the number of cells in the $\mathrm{G} 2 / \mathrm{M}$ phase decreased, and the expression of the genes associated with proliferation varied following inhibition of ILF3 $(\mathrm{P}<0.05)$. Positive expression of ILF3 was associated with a poor prognosis for patients with $\mathrm{GC}$, and was an independent risk factor for GC $(\mathrm{P}<0.05)$. In conclusion, ILF3 is involved in the deterioration of GC by promoting proliferation of GC cells, and ILF3 protein detection may assist in the prediction of the prognosis of patients with GC.
\end{abstract}

\section{Introduction}

Gastric cancer (GC) is a common malignancy in China, with the second-highest incidence and mortality rates in the country (1). Since GC develops rapidly and rarely causes symptoms in the early stages, the majority of patients present

Correspondence to: Dr Yong Li, Department of General Surgery, Hebei Medical University Fourth Affiliated Hospital and Hebei Provincial Tumor Hospital, 12 Jian-kang Road, Shijiazhuang, Hebei 050011, P.R. China

E-mail: liyong1958@hebmu.edu.cn

Key words: gastric cancer, interleukin enhancer-binding factor 3, gene interference, proliferation, prognosis with advanced-stage GC at their first hospital visit, making curative surgical treatment a challenge; the 5-year survival rate for the disease is $20-30 \%$, and the median survival time is only 11 months (2-4). The aggressive development of GC is closely associated with the strong proliferation capacity of the tumor cells (5); therefore, it is necessary to explore the mechanism underlying GC cell proliferation. It has been reported that interleukin enhancer-binding factor 3 (ILF3) regulates transcription, translation, mRNA stability and primary microRNA (pri-miRNA) processing; it may function as a transcriptional activator to regulate the mRNA synthesis of target genes (6). Abnormal expression of ILF3 has been identified in a number of malignancies, and ILF3 has been reported to be involved in tumor proliferation, invasion and metastasis (7-9). Nevertheless, few studies have been conducted to investigate the mechanism of action of ILF3 in GC. The present study detected ILF3 protein expression in tissues from paraffin-embedded samples. Subsequently, the ILF3 expression in GC cells was inhibited by small interfering RNAs (siRNAs). The cell proliferation and associated molecular mechanisms were investigated. Meanwhile, the clinical records of participants were obtained to evaluate the clinical significance of ILF3 detection, based on patient prognosis. The present study may provide evidence for further investigation of the role of ILF3 in GC development, and also suggested that ILF3 may be a novel prognostic marker for patients with GC.

\section{Materials and methods}

Clinical data. A total of 80 patients with GC who underwent surgery to remove the primary lesions at Hebei Medical University Fourth Affiliated Hospital (Shijiazhuang, China) between January 2010 and December 2011, while not receiving any other treatment for cancer prior to surgery (radiotherapy, chemotherapy, targeted therapy etc.), were recruited, and paraffin-embedded samples from their tumorous and adjacent mucosal tissues were obtained. The adjacent tissues exhibited no trace of cancerous cell or signs of atypical hyperplasia under microscopy. There were 57 males and 23 females with mean age of 55.82 \pm 8.54 years, with a range of 38-78 years. The research was approved by the Ethics Committee of Hebei Medical University Fourth Affiliated Hospital and informed consent was obtained from all participants. 
Reagents. Rabbit-anti-human polyclonal antibodies, including ILF3 (cat. no. HPA001897), p16 (cat. no. SAB4500072), p21 (cat. no. SAB4500065), Cyclin D1 (cat. no. SAB4502603) and GAPDH (cat. no. SAB2108266), were produced by Sigma-Aldrich (Merck KGaA, Darmstadt, Germany). Immunohistochemistry (IHC) kits and reagents were purchased from ZSGB-BIO (cat. no. SP-9001; OriGene Technologies, Inc., Beijing, China). Dulbecco's modified Eagle's medium (DMEM), fetal bovine serum (FBS) and trypsin solution were supplied by Gibco (Thermo Fisher Scientific, Inc., Waltham, MA, USA). MTT was obtained from Sigma-Aldrich (Merck $\mathrm{KGaA}$ ). All polymerase chain reaction (PCR) primers and siRNAs targeting ILF3 were synthesized by Sangon Biotech Co., Ltd. (Shanghai, China). Lipofectamine ${ }^{\circledR} 2000$ reagent was obtained from Invitrogen (Thermo Fisher Scientific, Inc.).

IHC assay and scoring of results. Tissue was fixed in $4 \%$ formalin for $24 \mathrm{~h}$ at room temperature and embedded in paraffin. Sections (4- $\mu \mathrm{m}$ thickness) were cut from paraffin blocks, deparaffinized and rehydrated in a graded alcohol series and distilled water. The slides were immersed in citrate buffer (0.01 M, pH 6.0) antigen retrieval buffer and boiled for $3 \mathrm{~min}$. Endogenous peroxidase activity was blocked with $3 \% \mathrm{H}_{2} \mathrm{O}_{2}$ for $20 \mathrm{~min}$. Sections were blocked in normal goat serum (5\%; cat. no. SP-9001; ZSGB-BIO; OriGene Technologies, Inc.) at $37^{\circ} \mathrm{C}$ for $30 \mathrm{~min}$ and then incubated with monoclonal antibody against ILF3 (1:100) overnight at $4^{\circ} \mathrm{C}$, followed by incubation with goat anti-rabbit polyclonal biotin-conjugated antibody (1:100; cat. no. SP-9001; ZSGB-BIO; OriGene Technologies, Inc.) at $37^{\circ} \mathrm{C}$ for $15 \mathrm{~min}$. Then, the horseradish peroxidase (HRP)-conjugated streptavidin working solution was added and incubated at $37^{\circ} \mathrm{C}$ for $15 \mathrm{~min}$. Subsequently, DAB substrate-chromogen solution (1:100; ZSGB-BIO; OriGene Technologies, Inc.) was applied to the samples to detect expression. Images were captured under a light microscope (magnification, $\mathrm{x} 400$ ) using a digital camera (Olympus DP25; Olympus Corporation, Tokyo, Japan); five randomly selected fields were analyzed per sample. The results were scored by two pathologists using a bi-parametric scoring system based on the quantity of cells with different staining intensities between 0 and $3(0,<25 \% ; 1,25-50 \% ; 2,51-75 \%$; $3,>76 \%)$ and the intensity of staining between 0 and $3(0$, no positive staining; 1 , light yellow; 2 , yellow; 3 , brownish yellow). The summation of the two scores was marked as follows: $0,-;$ $1-2,+; 3-4,++$; and 5-6, +++. ILF3 staining was considered positive if the summation score was $>0$.

Cell lines and cell culture. Gastric cell lines BGC823, AGS and SGC7901, and the gastric epithelial cell line GES-1 were obtained from the American Type Culture Collection (Manassas, VA, USA), and were preserved in the Research Centre of Hebei Medical University Fourth Affiliated Hospital. These cell lines were cultured in standard DMEM supplemented with $10 \%$ FBS. The incubators were maintained at $5 \% \mathrm{CO}_{2}$ and $37^{\circ} \mathrm{C}$. Among these GC cells, BGC823 and AGS are poorly differentiated gastric adenocarcinoma cell lines, while SGC7901 is a moderately differentiated gastric adenocarcinoma cell line.

ILF3-siRNA transfection and groupings. ILF3-siRNA (5'GCGGAUCCGACUACAACUACG-3') and the negative control (5'CGGCUGCAAUCGAUUGAUAGC-3') were purchased from Guangzhou RiboBio Co., Ltd. (Guangzhou, China). Transfection of ILF3 specific siRNA and the negative control were performed at a concentration of $20 \mu \mathrm{mol} / 1$ using Lipofectamine 2000 reagent. According to the manufacturer's protocol, $24 \mathrm{~h}$ prior to transfection, $5 \times 10^{5} \mathrm{BGC} 823$ and SGC7901 cells/well in $2 \mathrm{ml}$ DMEM were seeded into 6-well plates and cultured at $5 \% \mathrm{CO}_{2}$ and $37^{\circ} \mathrm{C}$. At $24 \mathrm{~h}$ later, when the cells had reached $70 \%$ confluence, transfection was performed. ILF3-siRNA and negative control siRNA were transfected into BGC823 and SGC7901 cells. At 48 h post-transfection, the subsequent experiments were performed. Experiments were repeated three times.

Cell activity assay (MTT assay). Each group of cells was seeded in 96-well plates at a density of $5 \times 10^{4}$ cells $/ \mathrm{ml}$. Following $4 \mathrm{~h}$ of incubation, a volume of $20 \mu \mathrm{l}$ MTT reagent $(5 \mathrm{mg} / \mathrm{ml})$ was added to each well, and cells were incubated for a further $4 \mathrm{~h}$. Then, the culture medium was discarded, followed by the addition of $150 \mu \mathrm{l}$ dimethyl sulfoxide to each well with gentle agitation for $15 \mathrm{~min}$ at room temperature. The optical density (OD) was obtained at $490 \mathrm{~nm}$ using a microtiter plate reader. Experiments were repeated three times.

Flow cytometry for cell cycle analysis. Cells were centrifuged at 2,000 RPM/447.2 x g for $15 \mathrm{~min}$ at $37^{\circ} \mathrm{C}$ for collection and rinsed twice with PBS. Pre-chilled $70 \%$ ethanol was added and stored at $4^{\circ} \mathrm{C}$ overnight. Again, the cells were centrifuged at 2,000 RPM/447.2 x g for $15 \mathrm{~min}$ at $37^{\circ} \mathrm{C}$ and resuspended once in $1 \mathrm{ml}$ PBS. Subsequently, $50 \mu \mathrm{g} / \mathrm{ml}$ propidium iodide, $100 \mu \mathrm{g} / \mathrm{ml}$ RNase A and $0.2 \%$ Triton X-100 PBS were added into $100 \mu \mathrm{l}$ of a $1 \times 10^{6}$ cells $/ \mathrm{ml}$ suspension. After a $30-\mathrm{min}$ incubation at $4^{\circ} \mathrm{C}$ in the dark, the cell cycle was detected using a flow cytometer (Epics-XL II; Beckman Coulter, Inc., Brea, CA, USA) and analyzed using Expo 32 ADC XL4 (Beckman Coulter, Inc.). Experiments were repeated three times.

Detection of target gene $m R N A$ by reverse transcription-quantitative PCR $(R T-q P C R)$. Total RNA was extracted using TRIzol ${ }^{\circledR}$ reagent (Thermo Fisher Scientific, Inc.), according to the manufacturer's instructions. Total RNA $(2 \mu \mathrm{g})$ was reverse transcribed into cDNA using an A5000 GoScript Reverse Transcription System (Promega Corporation, Madison, WI, USA) under the following conditions: $25^{\circ} \mathrm{C}$ annealing for $5 \mathrm{~min}, 42^{\circ} \mathrm{C}$ extension for $60 \mathrm{~min}$ and $70^{\circ} \mathrm{C}$ inactivation of reverse transcriptase for $15 \mathrm{~min}$. PCR was conducted using an A6001 GoTaq(R) RT-qPCR Master Mix (Promega Corporation). qPCR in a $25 \mu$ l total volume was established and performed over 45 cycles under the following conditions: $95^{\circ} \mathrm{C}$ annealing for $5 \mathrm{~min}, 95^{\circ} \mathrm{C}$ denaturation for $30 \mathrm{sec}$ and $72^{\circ} \mathrm{C}$ extension for $30 \mathrm{sec}$. The quantification cycle $\left(\mathrm{C}_{\mathrm{q}}\right)$ was calculated with the amplification curve using GAPDH as an internal standard (10). The sequences of each primer are presented in Table I. Experiments were repeated three times.

Western blot assay for the examination of candidate proteins. Total proteins were extracted from the cell lines using RIPA lysis buffer (Beijing Solarbio Science \& Technology Co., Ltd., Beijing, China) supplemented with $1 \mathrm{X}$ protease inhibitor cocktail (Roche Applied Science, Mannheim, Germany). The 
Table I. Sequences of each primer.

\begin{tabular}{lll}
\hline Gene & \multicolumn{1}{c}{ Forward primer $\left(5-3^{\prime}\right)$} & \multicolumn{1}{c}{ Reverse primer $\left(5^{\prime}-3^{\prime}\right)$} \\
\hline ILF3 & GTGTCCAATCACCAGTCCTG & GCTGAAGAAGTGGGAGTGTAGC \\
p16 & GAGAAACCTCGGGAAACTTAG & GGGTGATGGCATTTACAGGT \\
p21 & CATCCCGTGTTCTCCTTT & ACTCTTCATTTGTCTACCGTG \\
Cyclin D1 & ACCTGAGGAGCCCCAACAAC & GCTTCGATCTGCTCCTGGC \\
GAPDH & GACCCCTTCATTGACCTCAAC & CGCTCCTGGAAGATGGTGAT
\end{tabular}

ILF3, interleukin enhancer-binding factor 3.

protein concentration was determined using a bicinchoninic acid protein assay kit (Thermo Fisher Scientific, Inc.). Protein samples $(40 \mu \mathrm{g})$ were loaded into each well and separated via $12 \%$ SDS-PAGE. Proteins were transferred from the gel to a polyvinylidene fluoride membrane, followed by blocking for $1 \mathrm{~h}$ in 5\% skim milk in TBS at room temperature. Subsequently, the membrane was incubated in the primary antibodies $(1: 1,000)$ at $4^{\circ} \mathrm{C}$ overnight. Following three washes with TBS with Tween-20, the membrane was incubated with an alkaline phosphatase-conjugated goat anti-rabbit IgG secondary antibody (1:2,000; cat. no. A3687; Sigma-Aldrich; Merck KGaA) at room temperature for $1 \mathrm{~h}$. Protein bands were detected using an Odyssey system (LI-COR Biosciences, Lincoln, NE, USA). Expression was normalized to GAPDH. Image J v1.48 software (National Institutes of Health, USA) was used to quantify protein expression. Experiments were repeated three times.

Statistical analysis. All data were presented as the mean \pm standard deviation. SPSS version 19.0 (IBM Corp., Armonk, NY, USA) was utilized for data analysis. A $\chi^{2}$ test, Spearman correlation analysis, one-way analysis of variance followed by a least significant difference post hoc test, and the independent t-test were applied for experimental data examination. The Kaplan-Meier analysis was conducted for survival analysis; significant differences between patients positive for ILF3 expression and those a lack of expression were determined using the log-rank test. Multivariate survival analysis was performed using a Cox regression model (forward stepwise-likelihood ratio). $\mathrm{P}<0.05$ was considered to indicate a statistically significant difference.

\section{Results}

ILF3 protein expression in tumorous and adjacent mucosal tissue, GC cell lines and GES-1. The IHC results showed 72.50 $\%(58 / 80)$ ILF3 positive staining in GC tissues compared to $13.75 \%(14 / 80)$ in the adjacent mucosal tissues. ILF3 expression in GC tissues was higher than that in cancer-adjacent mucosa $\left(\chi^{2}=48.89 ; \mathrm{P}<0.001 ;\right.$ Fig. 1$)$. ILF3 protein expression was highest in BGC823 and SGC7901 cells, as demonstrated by western blotting (Fig. 2).

Effect of ILF3-siRNA on ILF3 expression in BGC823 and SGC7901 cells. BGC823 and SGC7901 cells were transfected with ILF3-siRNA. After 48 h of siRNA exposure, the ability of ILF3-siRNA to inhibit ILF3 protein and mRNA expression was quantified by western blotting and RT-qPCR, respectively. The ILF3 expression at the mRNA and protein levels was significantly lower in the ILF3-siRNA group compared with the negative control group in BGC823 and SGC7901 cells $(\mathrm{P}<0.05$; Fig. 3).

Effect of ILF3-siRNA transfection on BGC823 and SGC7901 cell viability. The proportion of viable BGC 823 cells was $0.614 \pm 0.122$ at $48 \mathrm{~h}$ post-ILF3-siRNA transfection relative to at $0 \mathrm{~h}$, which was significantly lower than that of the cells in the negative control group $(0.975 \pm 0.128 ; \mathrm{t}=-5.001 ; \mathrm{P}<0.001$; data not shown) at the same time point. Similar results were confirmed in SGC7901 cells; the proportion of viable SGC7901 cells at $48 \mathrm{~h}$ post-ILF3-siRNA transfection was $0.582 \pm 0.126$ in the ILF3-siRNA group, which was significantly lower than that in the control group $(1.014 \pm 0.178 ; \mathrm{t}=-4.852 ; \mathrm{P}<0.001)$.

Effect of ILF3 inhibition on the BGC823 and SGC7901 cell cycle. A higher proportion of BGC823 and SGC7901 cells in the ILF3-siRNA transfected group were in the G0/G1 phase relative to the negative control group, whereas the number of cells in the G2/M phase in the ILF3-siRNA group was lower compared with the negative control group $(\mathrm{P}<0.05$; Table II and Fig. 4).

Effect of ILF3-siRNA on genes associated with cell proliferation in BGC823 and SGC7901 cells. The results from the RT-qPCR and western blot analyses showed a significant upregulation of p16 and p21 at the mRNA and protein levels in the ILF3-siRNA group compared with the control, while Cyclin D1 was significantly downregulated (Fig. 5).

Association of ILF3 protein expression with clinicopathological characteristics, and its prognostic value. Participants with positive ILF3 protein expression exhibited deeper tumor infiltration and higher rates of lymph node metastasis (both $\mathrm{P}<0.05$ ), and no associations were detected between ILF3 and other clinical pathological characteristics (Table III). Kaplan-Meier (K-M) analysis for ILF3 protein indicated a lower survival rate in participants with positive expression compared with a lack of expression $\left(\chi^{2}=15.683\right.$; $\mathrm{P}<0.001$; Fig. 6$)$. The results of the Cox survival analysis demonstrated that positive expression of ILF3, TNM staging, differentiation of cancer cells and distant metastasis were independent risk factors for patients with GC, suggesting that ILF3 may serve as a novel marker to predict the prognosis of patients with GC (Table IV). 

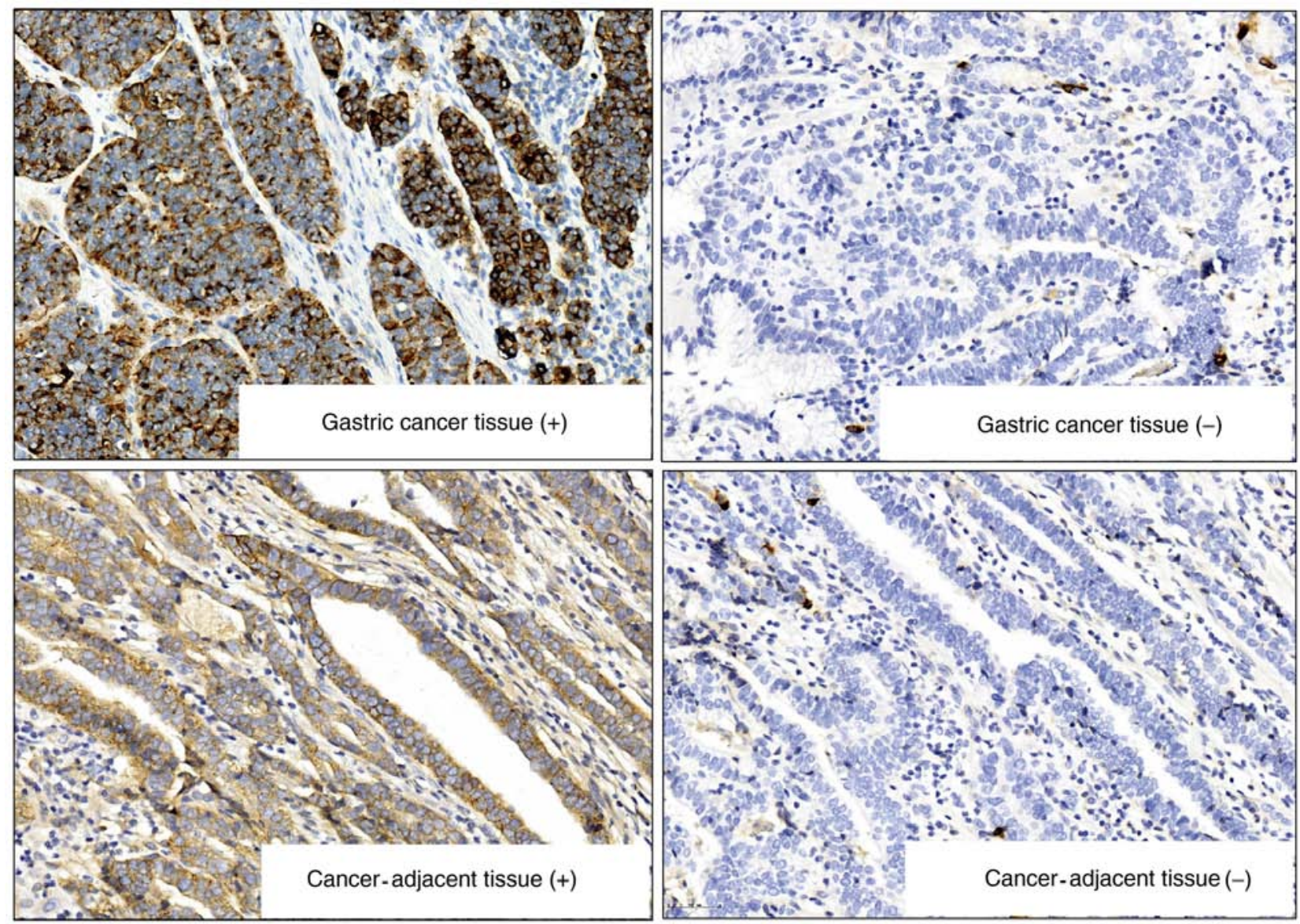

Figure 1. ILF3 protein expression in tissues of gastric cancer and adjacent mucosal tissues (IHC, x400 magnification). ILF3 protein expression was detected by IHC, predominantly in the cytoplasm with infrequent cell membrane expression. ILF3 positive staining in gastric cancer tissues was increased compared with that that in cancer-adjacent mucosa. ILF3, interleukin enhancer-binding factor 3; IHC, immunohistochemistry.
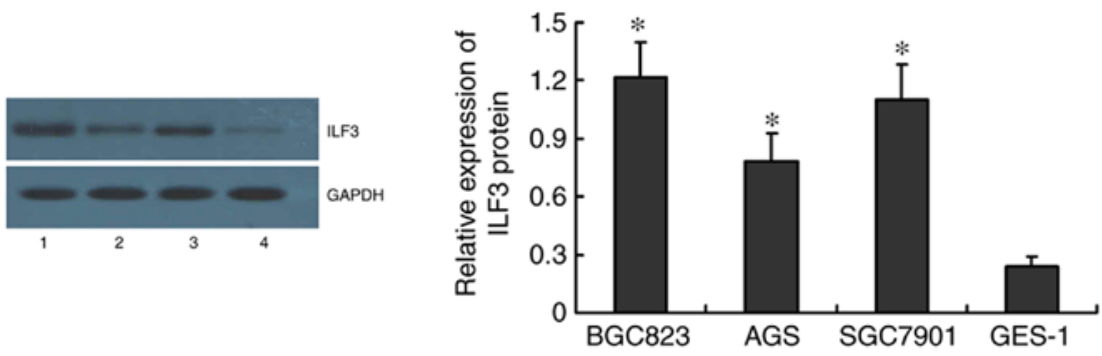

Figure 2. Expression of ILF3 protein in gastric cancer cell lines and the gastric epithelial cell line GES-1 (western blotting). In the western blot analysis, ILF3 protein exhibited significantly higher expression in gastric cancer cell lines compared with GES-1. In particular, BGC823 was verified to have the highest expression of ILF3 protein, followed by SGC7901 and AGS. Lane 1, BGC823; lane 2, AGS; lane 3, SGC7901; lane 4, GES-1. "P<0.01 vs. GES-1. ILF3, interleukin enhancer-binding factor 3 .

\section{Discussion}

GC is one of the most common cancers in China, with high mortality due to its aggressiveness, and poor prognosis (11-13). Although a number of genes and signaling pathways involved in GC development have been identified (14-17), the mechanism is still too sophisticated to be fully understood. Identifying novel genes closely associated with GC development is clinically necessary. ILF3 is a transcriptional coactivator which plays a regulatory role in the transcriptional activity of target genes (18-20). ILF3 has been verified to be aberrantly expressed in tumorous cells, and has been reported to be associated with tumor proliferation and metastasis, and to act as a regulator to its downstream genes such as Cyclins and p53 (7-9,21,22). However, its association with GC remains unclear. In this study, the role of ILF3 in GC was explored, and it was verified that ILF3 exhibited enhanced expression in GC tissues and cell lines, which suggested that ILF3 may be one of the factors underlying gastric carcinogenesis and development. ILF3 inhibition may possibly delay the progression of GC.

In present study, we detected ILF3 in GC cell lines, and BGC823, SGC7901 were selected to investigate the role of ILF3 in the development of GC, and the associated mechanism. 
Table II. Effect of ILF3-siRNA transfection on the cell cycle ( $\mathrm{n}=3$; cell \%).

BGC823 cells

Cell cycle stage

G0/G1

G2/M

$\mathrm{S}$
ILF3-siRNA group Negative control group
SGC7901 cells

ILF3-siRNA group Negative control group
$66.75 \pm 4.09^{\mathrm{a}}$
$14.81 \pm 4.94^{\mathrm{a}}$
$18.77 \pm 8.61$

$\begin{array}{ll}73.73 \pm 4.17^{\mathrm{a}} & 58.04 \pm 9.10 \\ 12.83 \pm 1.48^{\mathrm{a}} & 24.33 \pm 4.95 \\ 15.69 \pm 4.55 & 17.96 \pm 6.69\end{array}$

$18.77 \pm 8.61$

${ }^{a} \mathrm{P}<0.05$ vs. respective negative control group. ILF3, interleukin enhancer-binding factor 3; siRNA, small interfering RNA.

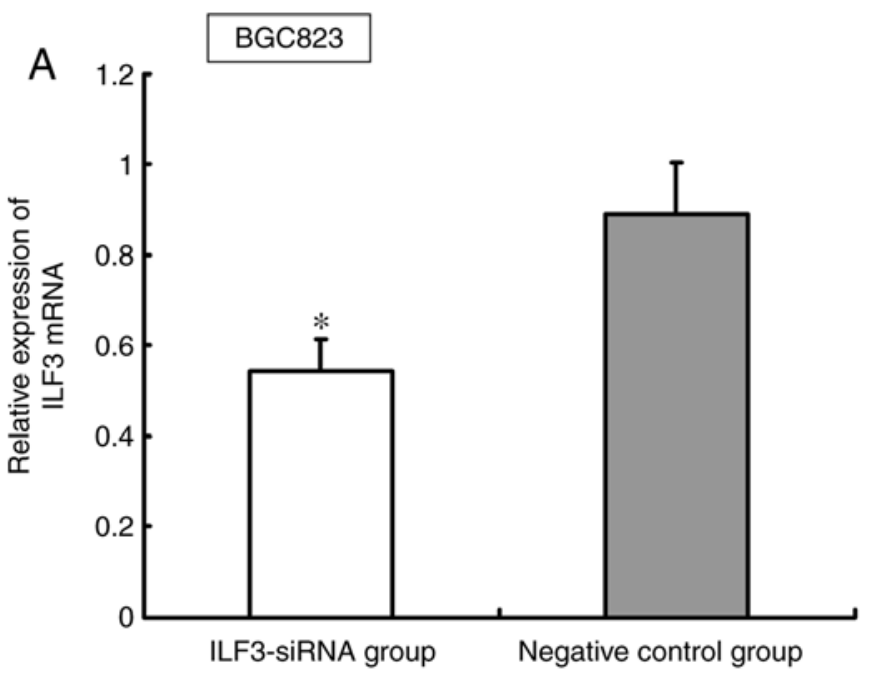

B
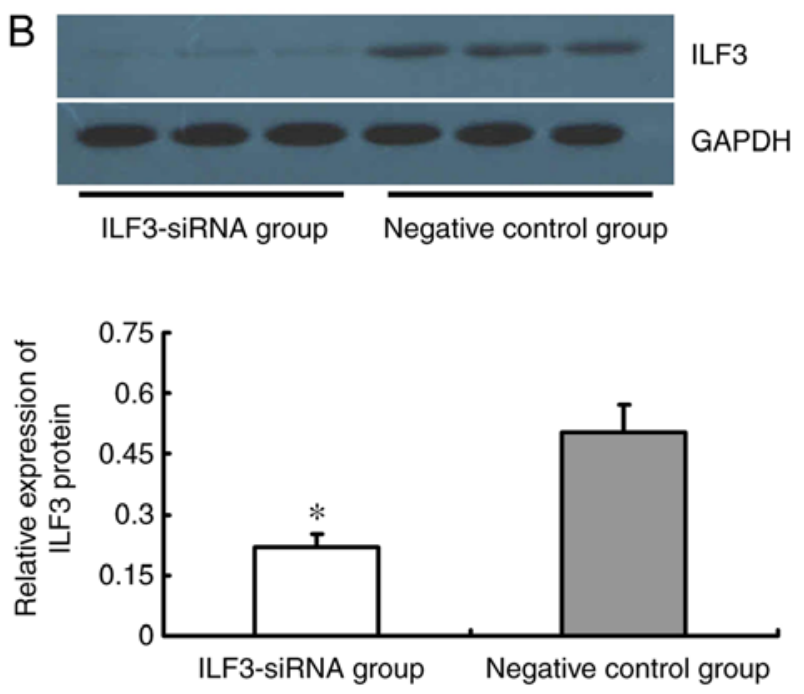

D
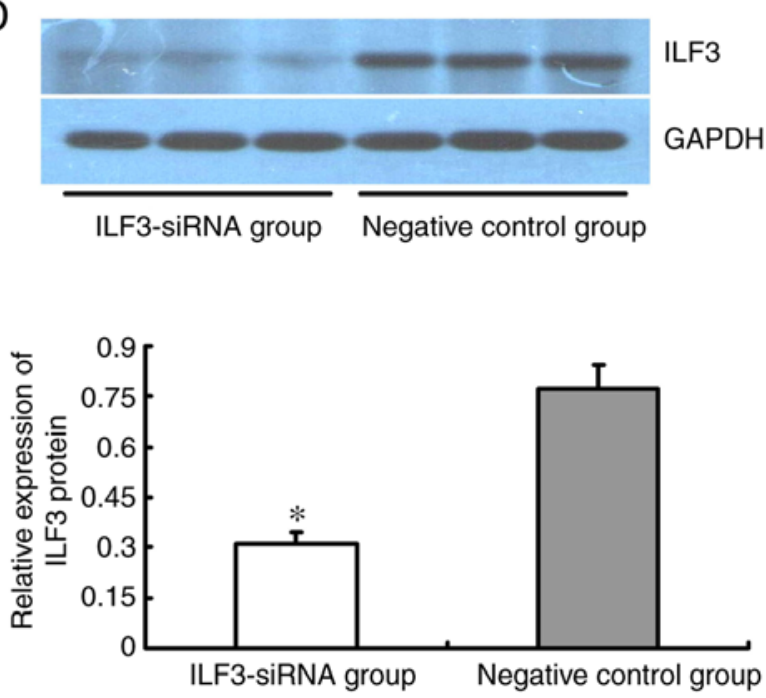

Figure 3. Effect of ILF3-siRNA treatment on ILF3 expression in BGC823 and SGC7901 cells (reverse transcription-quantitative polymerase chain reaction and western blotting). A total of $40 \mathrm{nmol} / 1$ of ILF3-siRNA or negative control siRNA was transfected to BGC 823 and SGC7901 cells respectively. The results demonstrated that the ILF3 (A) mRNA and (B) protein expression in BGC823 cells, and the (C) mRNA and (D) protein expression in SGC7901 cells, were significantly decreased compared with the respective negative control siRNA groups. ${ }^{~} \mathrm{P}<0.01$ vs. respective negative control group. siRNA, small interfering RNA; ILF3, interleukin enhancer-binding factor 3.

After ILF3 inhibition, BGC823 and SGC7901 cells exhibited weakened cell activity and an increased proportion of cells in the G0/G1 phase, which indicated that ILF3 might be associated with the promotion of gastric cancer cell proliferation. ILF3 may be a potential target in regulating growth of GC, and it is valuable to explore the detailed effect of ILF3 as a novel target to treat GC.

To investigate the mechanism underlying the role of ILF3 in cell proliferation in $\mathrm{GC}$, the present study further examined the expression of candidate genes in relation to cell growth after 


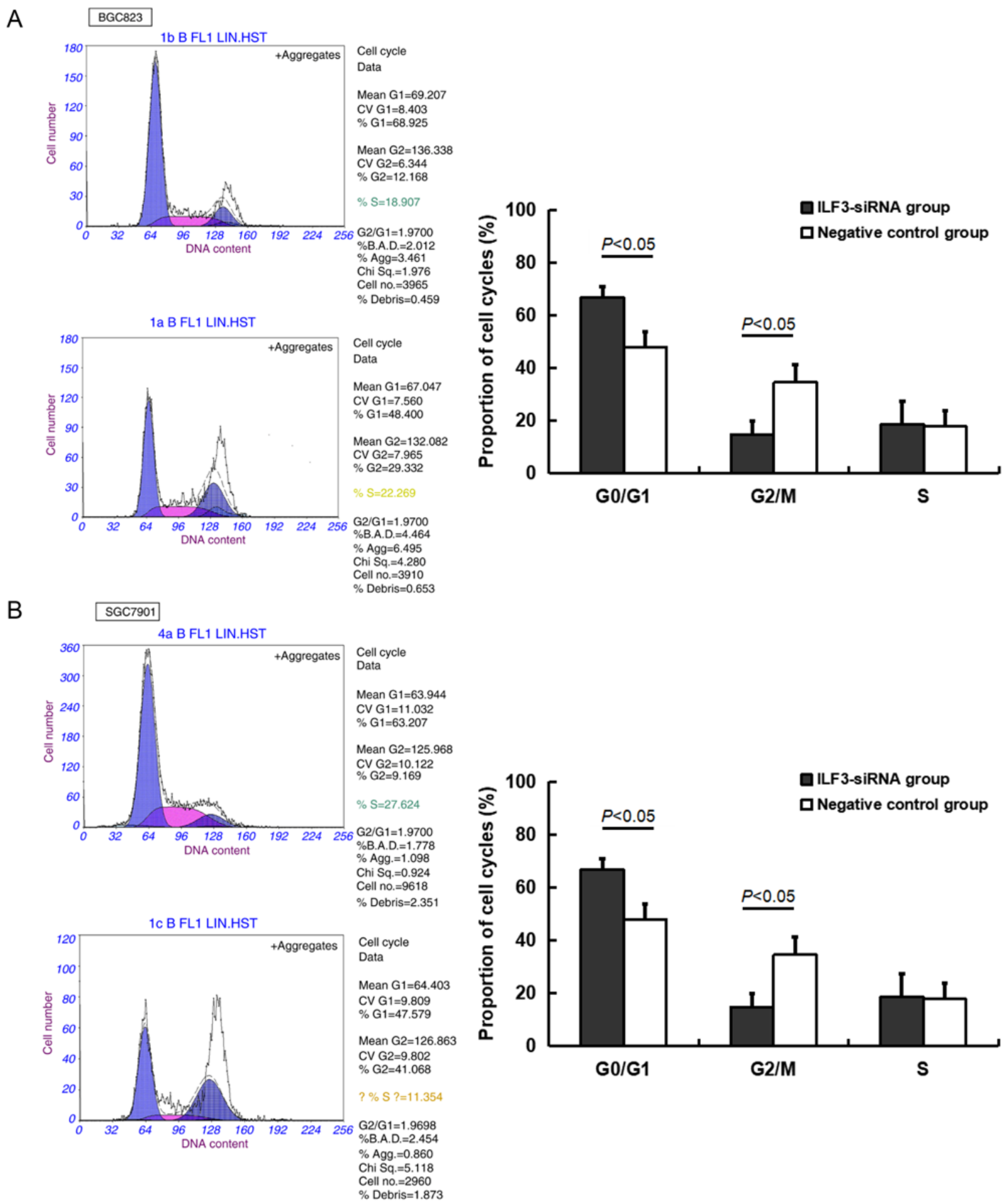

Figure 4. Effect of ILF3-siRNA transfection on the BGC823 and SGC7901 cell cycle. The FCM results demonstrated a larger proportion of cells in the G0/G1 phase in the ILF3-siRNA group compared with that in the negative control group, while the proportion of cells in the G2/M phase in the former group was smaller than in the control. (A) FCM results of the ILF3-siRNA transfection and negative control groups for BGC823 cells. (B) FCM results of the ILF3-siRNA transfection and negative control groups for SGC7901 cells. FCM, flow cytometry; siRNA, small interfering RNA; ILF3, interleukin enhancer-binding factor 3 .

ILF3 suppression. p16 functions in suppressing cell proliferation through regulation of the cell cycle $(23,24)$. p21 is an inhibitor of cyclin-dependent kinases (CDKs), which acts along with the p53 gene as a regulator of the cell cycle, participating in cancer suppression $(25,26)$. Cyclin D1, on the other hand, promotes cells proliferation, aiding tumor development $(27,28)$. In the present study, upregulation of p16 and p21 mRNA and protein in BGC823 and SGC7901 cells were confirmed following ILF3 suppression, while mRNA and protein of Cyclin D1 were downregulated. This finding suggested that ILF3 is likely to affect GC growth and progression through regulation of such genes as p16, p21 and Cyclin D1. However, further research into the molecular mechanism of ILF3 are needed, and the results should be verified by more experiments in vivo. 
Table III. Association between ILF3 protein expression and clinicopathological characteristics in gastric cancer.

ILF3 protein

Biological characteristics (n)

Negative, $n=22$

Positive, $n=58$

$\chi^{2}$ (P-value)

Sex

Male (55)

Female (25)

Age, years

$\geq 60$ (25)

$<60$ (55)

Diameter

$\geq 5 \mathrm{~cm}$ (39)

$<5 \mathrm{~cm}$ (41)

Serosal invasion

Negative (31)

Positive (49)

TNM staging

I-II (34)

III-IV (46)

Differentiation

Well (55)

Poorly (25)

Lymphatic metastasis

Positive (52)

Negative (28)

Nerve/vessel invasion

Positive (45)

Negative (35)

Distant metastasis

Positive (7)

Negative (73)
13

9

5

17

11

11

15

7

12

10

12

10

10

12

12

10

3

19
42

16

20

38

28

30

16

42

22

36

43

15

42

16

33

25

4

54
$1.318(0.251)$

$1.026(0.311)$

$0.019(0.890)$

$11.075(<0.001)$

$1.802(0.180)$

$2.850(0.091)$

$5.096(0.024)$

$0.036(0.850)$

$0.907(0.341)$

ILF3, interleukin enhancer-binding factor 3; TNM, Tumor-Node-Metastasis.

Table IV. Risk factors from Cox survival analysis for patients with gastric cancer.

$95.0 \%$ CI for $\operatorname{Exp}(\mathrm{B})$

\begin{tabular}{|c|c|c|c|c|c|c|c|c|}
\hline \multirow[b]{2}{*}{ Risk factor } & \multirow[b]{2}{*}{ B } & \multirow[b]{2}{*}{$\mathrm{SE}$} & \multirow[b]{2}{*}{ Wald } & \multirow[b]{2}{*}{ df } & \multirow[b]{2}{*}{ Sig. } & \multirow[b]{2}{*}{$\operatorname{Exp}(B)$} & \\
\hline & & & & & & & Lower & Upper \\
\hline ILF3 & 2.141 & 0.554 & 14.932 & 1 & 0.000 & 8.505 & 2.872 & 25.191 \\
\hline Invasion & 0.764 & 0.454 & 2.826 & 1 & 0.093 & 2.146 & 0.881 & 5.230 \\
\hline TNM stages & -1.163 & 0.475 & 5.992 & 1 & 0.014 & 0.312 & 0.123 & 0.793 \\
\hline Lymphatic & 0.213 & 0.488 & 0.191 & 1 & 0.662 & 1.238 & 0.476 & 3.219 \\
\hline Sex & -0.177 & 0.341 & 0.270 & 1 & 0.604 & 0.838 & 0.429 & 1.636 \\
\hline Age & -0.054 & 0.036 & 2.291 & 1 & 0.130 & 0.947 & 0.883 & 1.016 \\
\hline Differentiation & 0.647 & 0.320 & 4.091 & 1 & 0.043 & 1.910 & 1.020 & 3.575 \\
\hline Nerve vessel & -0.139 & 0.298 & 0.218 & 1 & 0.641 & 0.870 & 0.485 & 1.560 \\
\hline Distant & 1.620 & 0.505 & 10.298 & 1 & 0.001 & 5.054 & 1.879 & 13.595 \\
\hline
\end{tabular}

CI, confidence interval; ILF3, interleukin enhancer-binding factor 3; TNM, Tumor-Node-Metastasis; SE, standard error; df, degrees of freedom; Sig., significance; B, regression coefficient. 

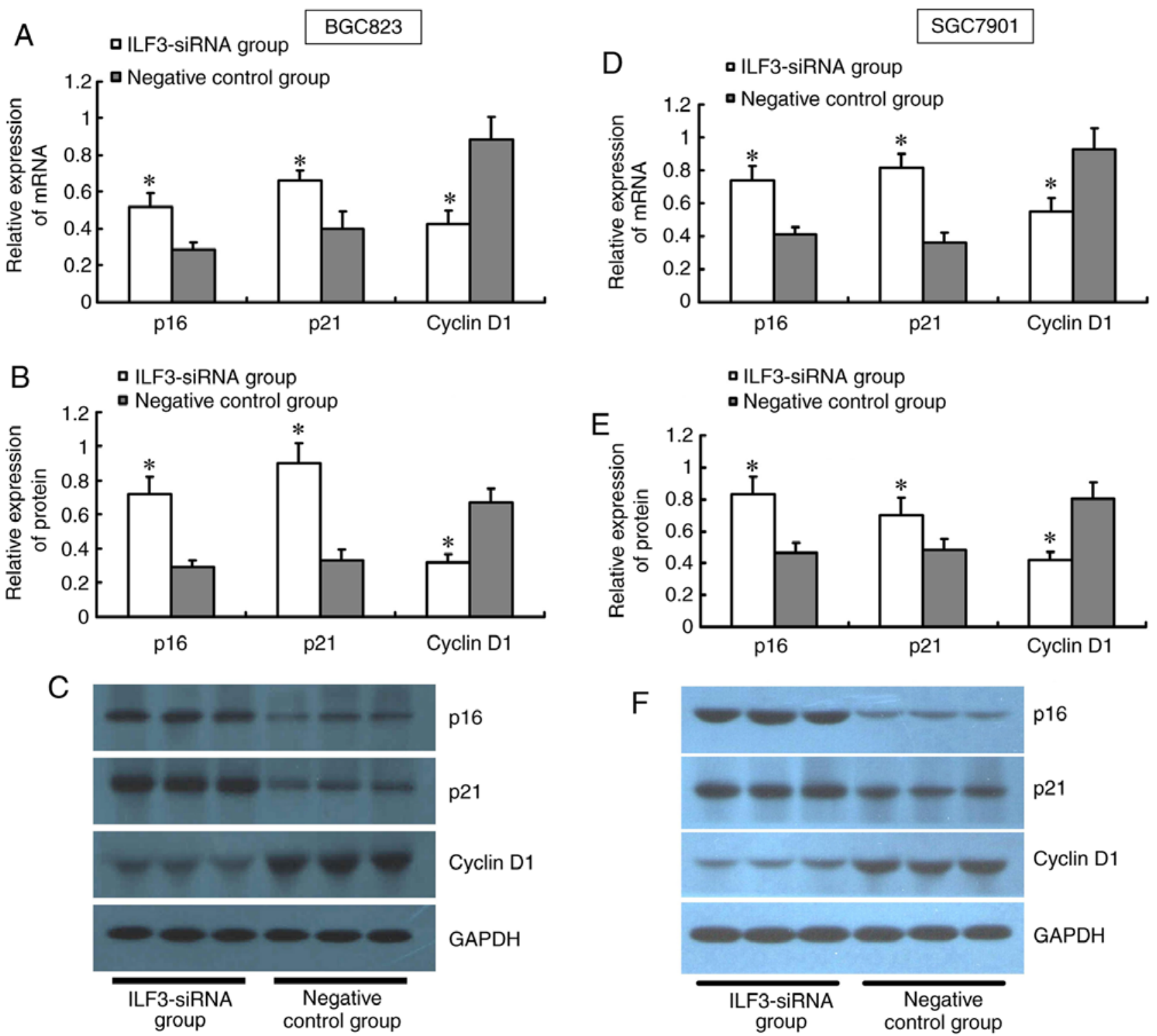

Figure 5. ILF3-siRNA treatment impacts upon p16, p21 and Cyclin D1 expression in BGC823 and SGC7901 cells. Using RT-qPCR and western blotting, in BGC823 and SGC7901 cells transfected with ILF3-siRNA, the mRNA and protein expression of p16, p21 and Cyclin D1 were significantly lower than that in the negative control group. For BGC823 cells: (A) Histogram of RT-qPCR results; (B) histogram of western blotting results; (C) representative image of SDS-PAGE. For SGC7901 cells: (D) Histogram of RT-qPCR results; (E) histogram of western blotting results; (F) representative image of SDS-PAGE. ${ }^{*} \mathrm{P}<0.01$ vs. respective negative control group. RT-qPCR, reverse transcription-quantitative polymerase chain reaction; siRNA, small interfering RNA; ILF3, interleukin enhancer-binding factor 3 .

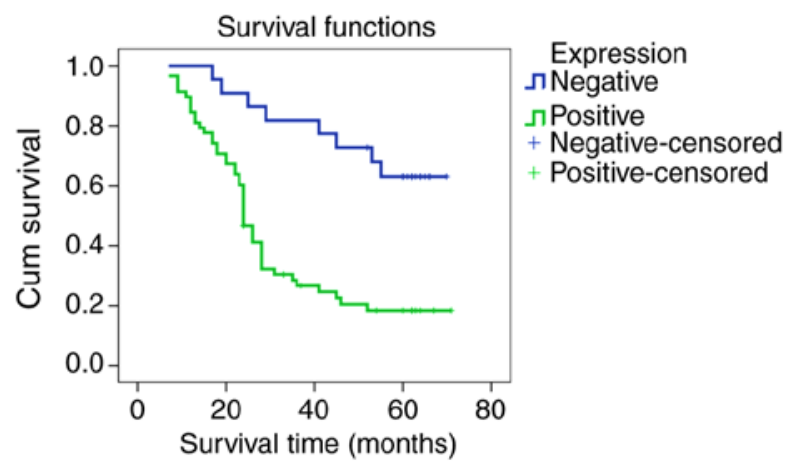

Figure 6. Kaplan-Meier survival curve for ILF3 protein expression associated with the prognosis of patients with gastric cancer. The results indicated a lower survival rate in participants with positive ILF3 expression compared with those without expression $\left(\chi^{2}=15.683 ; \mathrm{P}<0.001\right)$. Cum, cumulative; ILF3, interleukin enhancer-binding factor 3 .
To investigate the clinical value of ILF3 protein, the present study analyzed the relationship between ILF3 and the clinical and pathological characteristics of patients with GC. The results verified that positive ILF3 expression was associated with deeper tumor infiltration and higher rates of lymph node metastasis in patients with GC, suggesting that ILF3 overexpression may contribute to GC progression and metastasis. K-M prognostic analysis demonstrated that patients with positive expression of ILF3 protein had a lower survival rate than those with negative expression. In addition, based on Cox survival analysis, positive ILF3 protein expression is an independent risk factor of poor prognosis for patients with GC. These results indicated that positive ILF3 expression may be a novel prognostic marker for $\mathrm{GC}$, although further studies are required with more subjects, in addition to multiple-center studies, to confirm theses preliminary observations about the clinical value of ILF3. 
The present study indicated that overexpression of ILF3 protein in GC tissues is associated with poor prognosis in patients with GC. Moreover, ILF3 may promote the proliferation of GC through regulation of such genes as p16, p21 and Cyclin D1. The limitations of this study were that the sample size was limited and the detailed mechanism of ILF3 remains elusive. Despite these limitations, this study verified that ILF3 plays a crucial role in GC development. Further functional studies would be beneficial to evaluated outcomes in GC. Also, ILF3 is likely to become a novel therapeutic target in GC treatment.

\section{Acknowledgements}

Not applicable.

\section{Funding}

No funding was received.

\section{Availability of data and materials}

All data generated or analyzed during this study are included in this published article.

\section{Authors' contributions}

YüL and YoL conceived, designed and supervised the experiments. YüL, YZ, YaL, LF, NJ and QZ performed the experiments. The data were analyzed by YüL and YoL. YüL wrote the manuscript.

\section{Ethics approval and consent to participate}

The research was approved by the Ethics Committee of Hebei Medical University Fourth Affiliated Hospital and informed consent was obtained from all participants.

\section{Patient consent for publication}

Not applicable.

\section{Competing interests}

The authors declare that they have no competing interests.

\section{References}

1. Chen W, Zheng R, Baade PD, Zhang S, Zeng H, Bray F, Jemal A, $\mathrm{Yu}$ XQ and He J: Cancer statistics in China, 2015. CA Cancer J Clin 66: 115-132, 2016.

2. Wang W, Zheng C, Fang C, Li P, Xie J, Lin J, Zhan Y, Li W, Chen Y, Sun X, et al: Time trends of clinicopathologic features and surgical treatment for gastric cancer: Results from 2 high-volume institutions in southern China. Surgery 158: 1590-1597, 2015.

3. Li ZX and Kaminishi M: A comparison of gastric cancer between Japan and China. Gastric Cancer 12: 52-53, 2009.

4. Bolke E, Peiper M and Budach W: Capecitabine and oxaliplatin for advanced esophagogastric cancer. N Engl J Med 358: 1965, 2008.

5. Wang YJ, Liu JZ, Lv P, Dang Y, Gao JY and Wang Y: Long non-coding RNA CCAT2 promotes gastric cancer proliferation and invasion by regulating the E-cadherin and LATS2. Am J Cancer Res 6: 2651-2660, 2016.
6. Nakadai T, Fukuda A, Shimada M, Nishimura K and Hisatake K: The RNA binding complexes NF45-NF90 and NF45-NF110 associate dynamically with the c-fos gene and function as transcriptional coactivators. J Biol Chem 290: 26832-26845, 2015.

7. Agnoletto C, Brunelli L, Melloni E, Pastorelli R, Casciano F, Rimondi E, Rigolin GM, Cuneo A, Secchiero P and Zauli G: The anti-leukemic activity of sodium dichloroacetate in p53mutated/null cells is mediated by a p53-independent ILF3/p21 pathway. Oncotarget 6: 2385-2396, 2015.

8. Jiang W, Huang H, Ding L, Zhu P, Saiyin H, Ji G, Zuo J, Han D, Pan Y, Ding D, et al: Regulation of cell cycle of hepatocellular carcinoma by NF90 through modulation of cyclin E1 mRNA stability. Oncogene 34: 4460-4470, 2015.

9. Hu Q, Lu YY, Noh H, Hong S, Dong Z, Ding HF, Su SB and Huang S: Interleukin enhancer-binding factor 3 promotes breast tumor progression by regulating sustained urokinase-type plasminogen activator expression. Oncogene 32: 3933-3943, 2013.

10. Livak KJ and Schmittgen TD: Analysis of relative gene expression data using real-time quantitative PCR and the 2(-Delta Delta C(T)) method. Methods 25: 402-408, 2001.

11. Qiu M, Zhou Y, Jin Y, Wei XL, Wang DS, Ren C, Bai L, Yang DJ and Xu RH: Prognostic effect of high pretreatment neutrophil to lymphocyte ratio on survival of patients with gastric adenocarcinoma in China. Int J Biol Markers 30: e96-e103, 2015.

12. Li P, He HQ, Zhu CM, Ling YH, Hu WM, Zhang XK, Luo RZ, Yun JP, Xie D, Li YF and Cai MY: The prognostic significance of lymphovascular invasion in patients with resectable gastric cancer: A large retrospective study from Southern China. BMC Cancer 15: 370, 2015.

13. Liu Q, Bi JJ, Tian YT, Feng Q, Zheng ZX and Wang Z: Outcome after simultaneous resection of gastric primary tumour and synchronous liver metastases: survival analysis of a single-center experience in China. Asian Pac J Cancer Prev 16: 1665-1669, 2015.

14. Zhang J, Sun Z, Han Y, Yao R, Yue L, Xu Y and Zhang J: Rnf2 knockdown reduces cell viability and promotes cell cycle arrest in gastric cancer cells. Oncol Lett 13: 3817-3822, 2017.

15. Wei S, Li Q, Li Z, Wang L, Zhang L and Xu Z: Correction: miR-424-5p promotes proliferation of gastric cancer by targeting Smad3 through TGF- $\beta$ signaling pathway. Oncotarget 8: 34018 , 2017.

16. Jia S, Qu T, Wang X, Feng M, Yang Y, Feng X, Ma R, Li W, Hu Y, Feng Y, et al: KIAA1199 promotes migration and invasion by Wnt/ $\beta$-catenin pathway and MMPs mediated EMT progression and serves as a poor prognosis marker in gastric cancer. PLoS One 12: e0175058, 2017.

17. Li Y, Ye J, Chen Z, Wen J, Li F, Su P, Lin Y, Hu B, Wu D, Ning L, et al: Annonaceous acetogenins mediated up-regulation of Notch2 exerts growth inhibition in human gastric cancer cells in vitro. Oncotarget 8: 21140-21152, 2017.

18. Castella S, Bernard R, Corno M, Fradin A and Larcher JC: Ilf3 and NF90 functions in RNA biology. Wiley Interdiscip Rev RNA 6: 243-256, 2015.

19. Li T, Li X, Zhu W, Wang H, Mei L, Wu S, Lin X and Han X: NF90 is a novel influenza A virus NS1-interacting protein that antagonizes the inhibitory role of NS1 on PKR phosphorylation. FEBS Lett 590: 2797-2810, 2016.

20. Jayachandran U, Grey H and Cook AG: Nuclear factor 90 uses an ADAR2-like binding mode to recognize specific bases in dsRNA. Nucleic Acids Res 44: 1924-1936, 2016.

21. Wan C, Gong C, Ji L, Liu X, Wang Y, Wang L, Shao M, Yang L, Fan S, Xiao Y, et al: NF45 overexpression is associated with poor prognosis and enhanced cell proliferation of pancreatic ductal adenocarcinoma. Mol Cell Biochem 410: 25-35, 2015.

22. Masuda K, Kuwano Y, Nishida K, Rokutan K and Imoto I: NF90 in posttranscriptional gene regulation and microRNA biogenesis. Int J Mol Sci 14: 17111-17121, 2013.

23. Ovestad IT, Dalen I, Hansen E, Loge JL, Dybdahl BM, Dirdal MB, Moltu P and Berland JM: Clinical value of fully automated p16/Ki-67 dual staining in the triage of HPV-positive women in the Norwegian Cervical Cancer Screening Program. Cancer 125: 283-291, 2017.

24. Wang FL, Yang Y, Liu ZY, Qin Y and Jin T: Correlation between methylation of the p16 promoter and cervical cancer incidence. Eur Rev Med Pharmacol Sci 21: 2351-2356, 2017.

25. Wang LL, Guo HH, Zhan Y, Feng CL, Huang S, Han YX, Zheng WS and Jiang JD: Specific up-regulation of p21 by a small active RNA sequence suppresses human colorectal cancer growth. Oncotarget 8: 25055-25065, 2017. 
26. Li LH, Wu GY, Lu YZ, Chen XH, Liu BY, Zheng MH and Cai JC: p21-activated protein kinase 1 induces the invasion of gastric cancer cells through c-Jun NH2-terminal kinase-mediated activation of matrix metalloproteinase-2. Oncol Rep 38: 193-200, 2017.

27. Cheng R, Liu YJ, Cui JW, Yang M, Liu XL, Li P, Wang Z, Zhu LZ, Lu SY, Zou L, et al: Aspirin regulation of c-myc and cyclinD1 proteins to overcome tamoxifen resistance in estrogen receptor-positive breast cancer cells. Oncotarget 8: 30252-30302, 2017.
28. Kim Y, Kim H, Park D, Lee H, Lee YS, Choe J, Kim YM, Jeon D and Jeoung D: The pentapeptide Gly-Thr-Gly-Lys-Thr confers sensitivity to anti-cancer drugs by inhibition of CAGE binding to GSK $3 \beta$ and decreasing the expression of cyclinD1. Oncotarget 8: 13632-13651, 2017.

(c) (i) () This work is licensed under a Creative Commons cc. $\mathrm{EY}$ NO ND Attribution-NonCommercial-NoDerivatives 4.0 International (CC BY-NC-ND 4.0) License. 